Tropical Journal of Pharmaceutical Research April 2020; 19 (4): 759-764

ISSN: $1596-5996$ (print); 1596-9827 (electronic)

(C) Pharmacotherapy Group, Faculty of Pharmacy, University of Benin, Benin City, 300001 Nigeria.

\title{
Synergistic effect of a combination of granulocyte macrophage colony-stimulating factor and thymosin $\alpha 1$ on Lewis lung cancer transplanted tumor in mice
}

\author{
Haiyan Lan ${ }^{1 *}$, Yanrong Hao', Yanru Lv', Guangyu $\mathrm{Li}^{2}$, Yuncong $\mathrm{Mo}^{3}$, Cheng \\ Zheng $^{2}$, Yuanfa Li ${ }^{2}$ \\ ${ }^{1}$ Department of Oncological Internal Medicine, People's Hospital of Guangxi Zhuang Automous Region, ${ }^{2}$ Department of \\ Andrology, ${ }^{3}$ Department of Nuclear Medicine, The First Affiliated Hospital of Guangxi Medical University, Nanning, PR China \\ *For correspondence: Email: d157ox@163.com
}

Sent for review: 22 January 2019

Revised accepted: 26 January 2020

\begin{abstract}
Purpose: To study the synergistic effect of a combination of granulocyte-macrophage colonystimulating factor and thymosin- $\alpha 1$ on the treatment of Lewis lung cancer transplanted tumor.

Methods: C57BL/6 mice were used. A mouse model of Lewis lung cancer was established using Lewis lung cancer cell lines. The mice were randomly divided into blank control group, polyene taxol (DTX) group, DTX thymosin a1 (Ta-1) group, and DTX granulocyte-macrophage colony-stimulating factor (GM-CSF) group, with 8 mice per group. The degree of tumor inhibition, thymus mass, thymus index, spleen mass, spleen index, IL-6, TNF-1, IFN-1,CD4 $4^{+}, C D 8^{+} T$ cells and the ratio of $C D 4^{+} / C D 8^{+}$were determined by ELISA and flow cytometry.

Results: Body mass, thymus mass, thymus index, spleen mass, spleen index, IL-6, TNF-1, IFN-1, $C D 4^{+}, C D 8^{+} T$ cells and the ratio of $C D 4^{+} / C D 8^{+}$in $D T X+T \alpha-1$ group, DTX + GM-CSF group and DTX + $T \alpha-1+G M-C S F$ group were significantly elevated $(p<0.05)$, relative to the corresponding levels in DTX mice $(p<0.05)$. Body mass, degree of tumor inhibition, thymus mass, thymus index, spleen mass, spleen index, IL-6, TNF-1, IFN-1, CD4, CD8 T cells and CD4 $/ C D 8^{+}$ratio in DTX + Ta-1 + GM-CSF mice were significantly elevated, relative to the DTX $+T \alpha-1$ and DTX $+G M-C S F$ groups $(p<0.05)$. The state of the tumor was significantly improved in the DTX + Ta-1 and DTX + GM-CSF mice.

Conclusion: A combination treatment of GM-CSF, Ta-1 and DEX effectively enhances the resistance of mice and suppresses chemotherapy-induced decrease in body weight. This finding may be of clinical significance.
\end{abstract}

Keywords: Granulocyte macrophage, Colony-stimulating factor, Thymosin, Docetaxel, Lewis lung cancer, Transplanted tumor

This is an Open Access article that uses a fund-ing model which does not charge readers or their institutions for access and distributed under the terms of the Creative Commons Attribution License (http://creativecommons.org/licenses/by/4.0) and the Budapest Open Access Initiative (http://www.budapestopenaccessinitiative.org/read), which permit unrestricted use, distribution, and reproduction in any medium, provided the original work is properly credited.

Tropical Journal of Pharmaceutical Research is indexed by Science Citation Index (SciSearch), Scopus, International Pharmaceutical Abstract, Chemical Abstracts, Embase, Index Copernicus, EBSCO, African Index Medicus, JournalSeek, Journal Citation Reports/Science Edition, Directory of Open Access Journals (DOAJ), African Journal Online, Bioline International, Open-J-Gate and Pharmacy Abstracts

\section{INTRODUCTION}

Over the years, cases of lung cancer have become accentuated, making it the malignant tumor with the highest incidence [1]. Available data show that about 10,000 people in China are diagnosed with cancer every day, among which lung carcinoma patients and lung cancer-related 
deaths account for the largest proportion [2]. The cause of pulmonary cancer is not yet elucidated. However, studies have shown that lung cancer cases are markedly higher in habitual smokers than in the non-smoking individuals, and the younger the smoking age, the higher the prevalence of pulmonary cancer [3]. Moreover, the incidence of lung cancer in the urban population is markedly higher than that in rural dwellers, probably due to environmental pollution [3].

The clinical symptoms of early lung cancer are mild and often ignored, and most patients are diagnosed at the middle and late stages of the disease when they cannot benefit from operation [4]. Therefore, it is necessary to develop an effective and reliable chemotherapy to enhance clinical treatment for lung cancer. The treatment of lung cancer uses platinum-based chemotherapy, but the toxicity and side effects of chemotherapy limit its clinical application. The currently-used used drugs belong to the thirdgeneration chemotherapy medicines, an example of which is polyene taxol [5].

Docetaxel (DTX), which is extracted from the Chinese yew, has unique anti-cancer properties, and is used in clinical practice for treatment of lung cancer. However, serious adverse reactions and drug resistance have resulted in low levels of clinical effect [6]. The GM-CSF enhances immunity and promotes the release of proinflammatory factors. In addition, its receptor maintains normal neutrophil counts [7]. Studies have shown that combination of GM-CSF and chemotherapy significantly inhibits tumor growth, reduces the incidence of toxicity and side effects, and enhances the immunity of the patient [8].

Thymosin (Ta1) promotes the maturation of $\mathrm{CD}^{+} \mathrm{T}$ cells, directly kills target cells, and enhances immune response. Clinical investigations have revealed that Ta1 inhibits cancer proliferation and promotes apoptosis [9]. In this study, combination of Ta1 and GM-CSF was used to treat a mouse model of Lewis lung cancer, with the aim of determining their synergistic effects.

\section{EXPERIMENTAL}

\section{Animals}

Forty C57BL/6 mice were obtained from Guangdong Medical Experimental Animal Center. The mice were 4 - 5 weeks old, with a mean body mass of $21 \pm 3 \mathrm{~g}$. Mouse Lewis lung cancer cell line was obtained from Shanghai Yaji Biotechnology Co. Ltd.
This research was approved by the Animal Ethical Committee of Department of Oncological Internal Medicine, People's Hospital of Guangxi Zhuang Automous Region, Nanning City, Guangxi Province, China (approval no. 201834045), and was carried out in line with the directives of "Principles of Laboratory Animal Care" (NIH, 1985) [10].

\section{Reagents and instruments}

The drugs/reagents and instruments used, and their sources (in brackets) were: docetaxel (Lini Azeroth Biotechnology Co. Ltd), thymosin-a1 (Shanghai Kanglang Biotechnology Co. Ltd), GM-CSF (Nanjing Peptide Industry Biotechnology Co. Ltd), DMEM (Beijing Taizerda Science and Technology Co. Ltd), fetal bovine serum (Shenzhen Kangxi Biotech Co. Ltd), PBS buffer solution (Suzhou Heritage Biotech Co. Ltd.), $0.9 \%$ sodium chloride injection (Jiangxi Jiangblue Pure Biological Reagent Co. Ltd), tetramethylbenzidine (Sigma Co. Ltd), ether (Biotech Co. Ltd.), anhydrous ethyl ether (Beijing Dinghongsheng Biotechnology Co. Ltd), Enzyme-linked Immunoassay Kit (Beijing Shengqi Yangling Biotechnology Co. Ltd), heparin sodium (Nanjing Saurui Biotechnology Co. Ltd), and Hematoxylin-Eosin staining kit (Shenzhen Zike Biotechnology Co. Ltd).

The others were formaldehyde solution (Bioengineering Bioengineering Co. Ltd); doubleface super clean bench (Beijing TaizRuida Technology Co. Ltd); constant-temperature water bath box (Guangzhou Energy-Gathering Biotechnology Co. Ltd); electric-heating constanttemperature drying oven (Shanghai Chenlian Biotechnology Development Co. Ltd.); EP common PCR instrument (Hangzhou Baheng Technology Co. Ltd); centrifuge (Dexiang Technology Co. Ltd); horizontal electrophoresis apparatus (Shenzhen Kangyuan Source Co. Ltd), and medium-sized mechanical microwave oven (Granger Electric Co. Ltd).

All mice were inoculated with the Lewis cells to establish a mouse model of Lewis lung cancer. Then, the animals were assigned to blank control group, DTX group, DTX+Ta1group, DTX + GMCSF as well as DTX + Ta1 + GM-CSF groups.

The tumor size of each group was measured 3 times a week, and body mass and tumor size of mice in each group were monitored. After the last dose of $24 \mathrm{~h}$, the mice were weighed and sacrificed, and the tumor tissues were weighed. The percentage tumor inhibition was calculated as shown in Equation 1. 
$\mathrm{TI}(\%)=[(1-\mathrm{MTMe}) \times 100] / \mathrm{MTMb}$

where $\mathrm{TI}$ is tumor inhibition, MTMe is mean tumor mass in each group, and MTMb is mean tumor mass in the blank control group.

The thymus and spleen were weighed, and the thymus index and spleen index were calculated as fractions of body mass. The concentrations of IL-6, TNF-) and IFN- $\alpha$ were assayed using ELISA. Levels of $\mathrm{CD}^{+}$and $\mathrm{CD} 8^{+} \mathrm{T}$ cells were determined flow cytometric ally.

\section{Statistical analysis}

The results are expressed as mean \pm standard deviation (SD). Two-group comparisons were done with $t$-test using SPSS 3.0 software. Values of $p<0.05$ were considered as indicative of statistical significance of differences.

\section{RESULTS}

\section{Body mass, tumor mass and tumor inhibition}

The mass of mice in DTX, DTX + Ta1, DTX+GMCSF and DTX+Ta1+GM-CSF groups were markedly lower than corresponding blank control values $(p<0.05)$. The body mass was higher in DTX + Ta1 + GM-CSF mice than in DTX mice, and body mass of mice in DTX + Ta1 + GM-CSF group was markedly higher than that of mice in DTX + Ta1 and DTX + GM-CSF groups $(p<$ $0.05)$. These results are shown in Table 1. Relative to blank control, mice mass was markedly decreased in DTX, DTX + Ta1, DTX + GM-CSF and DTX + Ta1 + GM-CSF groups $(p<$ 0.05).
However, mice weight in DTX + TA1 + GM-CSF group was decreased, relative to DTX + Ta1, DTX + GM-CSF, and DTX groups $(p<0.05)$. The $\%$ anti-tumor effects in the DTX group, DTX + Ta1 group, DTX + GM-CSF group and DTX + Ta1 + GM-CSF group were markedly elevated, relative to blank control $(p<0.05)$. Tumor inhibition was markedly higher in DTX + Ta1 + GM-CSF mice than in DTX and DTX + Ta1 mice.

\section{Thymus and spleen indices}

The mass of thymus and the thymus index of DTX group, DTX+Ta1 group, DTX+GM-CSF group, DTX+ Ta1+GM-CSF group, as well as spleen mass and spleen index were significantly lower than the corresponding values in the blank control group $(p<0.05)$. The thymus mass, thymus index, spleen mass and spleen index of mice in DTX + Ta1 group, the DTX + GM - CSF group and the DTX + Ta1 + GM-CSF group were markedly higher than those of DTX-treated mice $(p<0.05)$. Moreover, thymus mass values of mice in DTX + Ta1 + GM - CSF group, thymus index, spleen mass and spleen index were markedly high, relative to mice in DTX + Ta1 and DTX + GM - CSF groups $(p<0.05$; Table 2$)$.

\section{Serum cytokine values}

Levels of TNF- $\alpha$, IL- 6 and IFN- $\gamma$ in DTX group, DTX + Ta1 mice, DTX + GM-CSF group and $\mathrm{DTX}+\mathrm{Ta} 1$ + GM - CSF group were markedly reduced, relative to the blank control group, while levels of IL-6, TNF- $\alpha$ and IFN- $\gamma$ of mice were markedly higher in DTX + Ta1 group, DTX + GMCSF group and DTX + Ta1 + GM-CSF group those in DTX-treated mice $(p<0.05)$.

Table 1: Mass of mouse and tumor inhibition rate

\begin{tabular}{lccc}
\hline Group & Mass of mouse $(\mathbf{g})$ & Mass of tumor $(\mathbf{g})$ & Inhibition (\%) \\
\hline Blank control & $32.62 \pm 2.02$ & $1.80 \pm 0.24$ & 0 \\
DTX & $23.47 \pm 2.13^{\mathrm{a}}$ & $1.23 \pm 0.12^{\mathrm{a}}$ & $34.11^{\mathrm{a}}$ \\
DTX + Ta1 & $24.87 \pm 1.53^{\mathrm{abc}}$ & $1.03 \pm 0.09^{\mathrm{abc}}$ & $46.12^{\mathrm{abc}}$ \\
DTX + GM - CSF & $25.90 \pm 1.46^{\mathrm{abc}}$ & $0.99 \pm 0.07^{\mathrm{abc}}$ & $48.01^{\mathrm{abc}}$ \\
DTX + Ta1 + GM - CSF & $27.64 \pm 1.53^{\mathrm{ab}}$ & $0.71 \pm 0.10^{\mathrm{ab}}$ & $65.33^{\mathrm{ab}}$ \\
\hline
\end{tabular}

${ }^{\mathrm{a}} P<0.05$, vs blank control; ${ }^{\mathrm{b}} p<0.05$, vs DTX mice, ${ }^{\mathrm{c}} p<0.05$, vs DTX + Ta1+ GM - CSF group

Table 2: Thymus index and spleen index of mice

\begin{tabular}{lcccc}
\hline Group & $\begin{array}{c}\text { Mass of } \\
\text { thymus }(\mathbf{m g})\end{array}$ & $\begin{array}{c}\text { Thymus } \\
\text { index }(\mathbf{m g} / \mathbf{g})\end{array}$ & Mass of spleen(mg) & $\begin{array}{c}\text { Spleen } \\
\text { index(mg/g) }\end{array}$ \\
\hline Blank control & $95.32 \pm 16.13$ & $3.04 \pm 0.84$ & $155.43 \pm 11.17$ & $4.89 \pm 0.56$ \\
DTX & $41.49 \pm 11.04^{\mathrm{a}}$ & $1.88 \pm 0.80^{\mathrm{a}}$ & $81.58 \pm 12.53^{\mathrm{a}}$ & $3.60 \pm 0.74^{\mathrm{a}}$ \\
DTX + Ta1 & $48.60 \pm 9.37^{\mathrm{abc}}$ & $2.06 \pm 0.79^{\mathrm{abc}}$ & $98.86 \pm 9.50^{\mathrm{abc}}$ & $4.10 \pm 0.83^{\mathrm{abc}}$ \\
DTX + GM - CSF & $49.49 \pm 9.74^{\mathrm{abc}}$ & $2.02 \pm 0.82^{\mathrm{abc}}$ & $99.74 \pm 10.36^{\mathrm{abc}}$ & $3.98 \pm 0.92^{\mathrm{abc}}$ \\
DTX + Ta1+ GM - & $59.45 \pm 9.08^{\mathrm{ab}}$ & $2.27 \pm 1.00^{\mathrm{ab}}$ & $118.57 \pm 11.20^{\mathrm{ab}}$ & $4.41 \pm 0.94^{\mathrm{ab}}$ \\
CSF & & &
\end{tabular}

${ }^{\mathrm{a}} P<0.05$, vs blank control; ${ }^{\mathrm{b}} p<0.05$, vs DTX mice, ${ }^{\mathrm{c}} p<0.05$, vs DTX + Ta $1+$ GM-CSF group 
Table 3: Serum cytokine levels $(\mathrm{pg} / \mathrm{mL})$

\begin{tabular}{|c|c|c|c|}
\hline Group & IL-6 & TNF- $\alpha$ & IFN-Y \\
\hline Blank control & $443.43 \pm 9.06$ & $612.39 \pm 7.00$ & $73.27 \pm 3.68$ \\
\hline DTX & $310.87 \pm 7.96^{a}$ & $356.24 \pm 6.38^{a}$ & $37.35 \pm 3.90^{a}$ \\
\hline $\mathrm{DTX}+\mathrm{Ta} 1$ & $357.65 \pm 7.04 \mathrm{abc}$ & $399.09 \pm 7.45^{a b c}$ & $47.35 \pm 3.14 \mathrm{abc}$ \\
\hline $\mathrm{DTX}+\mathrm{GM}-\mathrm{CSF}$ & $356.34 \pm 8.49 a b c$ & $412.36 \pm 7.30 \mathrm{abc}$ & $52.95 \pm 3.56 \mathrm{abc}$ \\
\hline $\mathrm{DTX}+\mathrm{Ta} 1+\mathrm{GM}-\mathrm{CSF}$ & $398.24 \pm 8.74^{\mathrm{ab}}$ & $498.16 \pm 6.43^{a b}$ & $61.50 \pm 3.39 a b$ \\
\hline
\end{tabular}

Table 4: T cell levels

\begin{tabular}{|c|c|c|c|}
\hline Group & $\mathrm{CD4}^{+}\left(10^{9} / \mathrm{L}\right)$ & $\mathrm{CD8}^{+}\left(10^{9} / \mathrm{L}\right)$ & $\mathrm{CD4}^{+} / \mathrm{CD8}^{+}(\%)$ \\
\hline Blank control & $15.37 \pm 0.53$ & $8.38 \pm 1.03$ & $2.43 \pm 1.00$ \\
\hline DTX & $9.89 \pm 0.63^{a}$ & $4.32 \pm 0.82^{a}$ & $1.95 \pm 0.67^{a}$ \\
\hline $\mathrm{DTX}+\mathrm{Ta} 1$ & $10.34 \pm 0.96 \mathrm{abc}$ & $5.24 \pm 0.75^{a b c}$ & $2.10 \pm 0.89 a b c$ \\
\hline $\mathrm{DTX}+\mathrm{GM}-\mathrm{CSF}$ & $13.45 \pm 0.59 \mathrm{abc}$ & $6.37 \pm 0.92^{a b c}$ & $2.12 \pm 1.03 a b c$ \\
\hline $\mathrm{DTX}+\mathrm{Ta} 1+\mathrm{GM}-\mathrm{CSF}$ & $14.67 \pm 0.80^{a b}$ & $7.30 \pm 1.05^{a b}$ & $2.24 \pm 0.95^{\mathrm{ab}}$ \\
\hline
\end{tabular}

Mice in DTX + Ta1 + GM-CSF group had significantly higher concentrations of these cytokines than those in DTX + Ta1 group and DTX + GM - CSF group $(p<0.05)$.

\section{T cell levels}

Table 4 shows that the number of $\mathrm{CD}^{+}$and $\mathrm{CD}^{+} \mathrm{T}$ cells and $\mathrm{CD}^{+} / \mathrm{CD}^{+}$ratio of mice in DTX group, DTX+ Ta1 group, DTX+ GM-CSF group and DTX+ Ta1+ GM-CSF group were significantly lower than values in blank control mice $(p<0.05)$. Moreover, the $\mathrm{CD}^{+}$and $\mathrm{CD}^{+} \mathrm{T}$ cell counts and $\mathrm{CD}^{+} / \mathrm{CD}^{+}$ratios of mice in DTX + Ta1 group, DTX + GM-CSF group and DTX + Ta1 + GM-CSF group were markedly higher than DTX-treated mice values $(p<0.05)$. The CD4 ${ }^{+}$ and $\mathrm{CD}^{+} \mathrm{T}$ cells and $\mathrm{CD} 4^{+} / \mathrm{CD}^{+}$ratio of mice in $\mathrm{DTX}+\mathrm{Ta} 1+\mathrm{GM}-\mathrm{CSF}$ group were markedly higher than those in DTX + Ta1 and DTX+ GMCSF groups $(p<0.05)$.

\section{DISCUSSION}

Lung cancer constitutes a serious threat to human life. The incidence of the disease has gradually increased, while the survival of patients has decreased, with a value of $25 \%$ for stage IIB lung cancer [11]. Surgery is the most effective strategy for early-stage lung cancer. Peripheral small lung cancer is associated with a 5-year survival of $80 \%$. Platinum-linked chemotherapy (the most representative of which is DTX) is popularly employed for treating individuals with advanced pulmonary carcinoma [12].

Docetaxel (DTX), a diterpenoid and a semisynthetic analogue of paclitaxel, is vital for maintaining vascular stability and initiating cytotoxicity. It enhances apoptosis of tumor cells more effectively than paclitaxel [13]. Docetaxel has been widely used in clinical practice with satisfactory results. However, the toxicity and side effects such as bone marrow suppression, neutrophilia and allergy due to DTX seriously affect the health of patients, leading to decline in their immune function and reduced drug tolerance. It has been reported that DTX suppresses immune response in mice due to atrophy of lymphoid organs and severe impairment of immune function [14].

The GM-CSF is a hematopoietic factor that maintains innate immune homeostasis, and its production is regulated by various cytokines and antigens. It was originally present as a proinflammatory factor, and has been confirmed as an immunoregulatory factor in other studies [15]. The GM-CSF receptor reduces the body's tolerance and inhibits tumor growth. At present, GM-CSF has become a widely used immune stimulation adjuvant in clinical practice. Immune cells are regulated by Ta1, which also enhances immune response and produces relevant biological effects on target cells. Thus, Ta1 is beneficial for the reduction of oxidative damage caused by chemotherapy drugs [16].

The results obtained in this study showed that body mass, tumor mass, thymus mass, thymus index, spleen mass, spleen index, IL-6, TNF- $\alpha$, IFN- $y, \quad \mathrm{CD}^{+}, \quad \mathrm{CD}^{+} \mathrm{T}$ cell number and $\mathrm{CD}^{+} / \mathrm{CD}^{+}$ratio in $\mathrm{DTX}+\mathrm{Ta} 1$ group, DTX + GM-CSF group, and DTX + Ta1 + GM-CSF group were markedly reduced, when compared with blank control values, and \% tumor inhibition was markedly higher than values in blank control, $\mathrm{DTX}+\mathrm{Ta} 1$ and DTX + GM-CSF groups. Moreover, body mass, thymus mass, thymus index, spleen mass, spleen index, IL-6,TNF-a, IFN- $\mathrm{Y}, \mathrm{CD}^{+}, \mathrm{CD}^{+} \mathrm{T}$ cell number and $\mathrm{CD}^{+} / \mathrm{CD}^{+}$ratio in $\mathrm{DTX}+\mathrm{Ta} 1+\mathrm{GM}-\mathrm{CSF}$ group were significantly higher than those in DTX, DTX + Ta 1 and DTX + GM-CSF groups. In addition, 
tumor mass values in DTX + Ta 1 and DTX+GMCSF groups were markedly decreased, relative to those in DTX + Ta 1 and DTX + GM-CSF groups. These findings indicate that combined treatment with GM-CSF and Ta 1 effectively alleviates DTX-induced decreases in body mass and inhibits tumor growth in mice, while effectively alleviating DTX-induced thymic and splenic injuries. Moreover, the combination treatment can reverse the DTX-induced increases in levels of cytokines, suppress decreases in $T$ cell number, and increase the population of $\mathrm{T}$ cells.

\section{CONCLUSION}

These results indicate that GM-CSF-Ta1-DEX combination treatment effectively enhances the resistance of mice and suppresses body mass reduction caused by chemotherapy. At the same time, it can effectively reduce the levels of cytokines, and enhance $\mathrm{T}$ lymphocyte-mediated cellular immunity. Low immunity may be a predisposing factor for tumors, and the occurrence of tumor may also lead to the suppression of anti-tumor immunity. Thus, the enhancement of immune function of tumor patients is an important clinical treatment strategy.

\section{DECLARATIONS}

\section{Acknowledgement}

This study was supported by Natural Science Foundation of Guangxi Zhuang Autonomous Region (no. 2017GXNSFAA198062).

\section{Conflict of interest}

No conflict of interest is associated with this work.

\section{Contribution of authors}

We declare that this work was done by the author(s) named in this article and all liabilities pertaining to claims relating to the content of this article will be borne by the authors. All authors read and approved the manuscript for publication. Haiyan Lan conceived and designed the study, Haiyan Lan, Yanrong Hao, Yanru Lv, Guangyu Li, Yuncong Mo, Cheng Zheng, while Yuanfa Li collected and analysed the data. Haiyan Lan wrote the manuscript.

\section{Open Access}

This is an Open Access article that uses a funding model which does not charge readers or their institutions for access and distributed under the terms of the Creative Commons Attribution License (http://creativecommons.org/licenses/by/ 4.0) and the Budapest Open Access Initiative (http://www.budapestopenaccessinitiative.org/rea d), which permit unrestricted use, distribution, and reproduction in any medium, provided the original work is properly credited.

\section{REFERENCES}

1. Du L, Herbst RS, Morgensztern D. Immunotherapy in Lung Cancer. Hematol Oncol Clin North Am 2017; 31(1): 131-141.

2. El-Osta $H$, Jani $P$, Mansour $A$, Rascoe $P$, Jafri $S$. Endobronchial Ultrasound for Nodal Staging of NonSmall Cell Lung Cancer Patients with Radiologically Normal Mediastinum: A Meta-Analysis. Ann Am Thorac Soc 2018; 15(7): 864-874.

3. Yu XJ, Chen G, Yang J, Yu GC, Zhu PF, Jiang ZK, Feng $K$, Lu Y, Bao B, Zhong FM. Smoking alters the evolutionary trajectory of non-small cell lung cancer. Exp Ther Med 2019; 18(5): 3315-3324.

4. Abbosh C, Birkbak NJ, Wilson GA, Jamal-Hanjani $M$, Constantin $T$, Salari $R$, Le Quesne J, Moore DA, Veeriah $S$, Rosenthal $R$, et al. Phylogenetic ctDNA analysis depicts early stage lung cancer evolution. Nature 2017; 545(7655): 446-451.

5. Sonobe M, Yutaka Y, Nakajima D, Hamaji M, Menju T, Ohsumi A, Chen-Yoshikawa TF, Sato $T$, Date $H$. Salvage Surgery After Chemotherapy or Chemoradiotherapy for Initially Unresectable Lung Carcinoma. Ann Thorac Surg 2019; 108(6): 1664-1670.

6. Raymundo $S$, Muller VV, Andriguetti NB, Tegner $M$, Artmann AC, Kluck HM, Franzoi MA, Vilela RMM, Schwartsmann G, Linden $R$, et al. Determination of docetaxel in dried blood spots by LC-MS/MS: Method development, validation and clinical application. J Pharm Biomed Anal 2018; 157: 84-91.

7. Wang TT, Zhao YL, Peng LS, Chen N, Chen $W, L V Y P$, Mao FY, Zhang JY, Cheng $P$, Teng YS, et al. Tumouractivated neutrophils in gastric cancer foster immune suppression and disease progression through GM-CSFPD-L1 pathway. Gut 2017; 66(11): 1900-1911.

8. Ahn S, Jeong D, Oh SJ, Ahn J, Lee SH, Chung DH. GMCSF and IL-4 produced by NKT cells inversely regulate IL-1 $\beta$ production by macrophages. Immunol Lett 2017; 182: $50-56$.

9. Back SE, Mccauley JL, Korte KJ, Gros DF, Leavitt V, Gray KM, Hamner MB, DeSantis SM, Malcolm R, Brady $K T$, et al. A Double-Blind, Randomized, Controlled Pilot Trial of N-Acetylcysteine in Veterans With Posttraumatic Stress Disorder and Substance Use Disorders. J Clin Psychiatry 2016; 77(11): 1439.

10. World Health Organization. Principles of laboratory animal care. WHO Chron 1985; 39: 51-56.

11. Lambros L, Guibourg B, Uguen A. ROS1-rearranged Non-Small Cell Lung Cancers with Concomitant

Trop J Pharm Res, April 2020; 19(4):763 
Oncogenic Driver Alterations: About Some Rare Therapeutic Dilemmas. Clin Lung Cancer 2018; 19(1): 73-74.

12. Rafiei P, Haddadi A. Docetaxel-loaded PLGA and PLGA$P E G$ nanoparticles for intravenous application: pharmacokinetics and biodistribution profile. Int $J$ Nanomed 2017; 12: 935-947.

13. Kun M, Xinxin Z, Feifan Z, Lin M. Unresectable Recurrent Squamous Cell Carcinoma of the Temporal Bone Treated by Induction Chemotherapy Followed by Concurrent Chemo-Reirradiation: A Case Report and Review of the Literature. Otol Neurotol 2015; 36(9): 1543-1546.

14. Ito $S$, Sano $T$, Mizusawa J, Takahari D, Katayama $H$, Katai H, Kawashima $Y$, Kinoshita T, Terashima M,
Nashimoto A, et al. A phase II study of preoperative chemotherapy with docetaxel, cisplatin, and S-1 followed by gastrectomy with D2 plus para-aortic lymph node dissection for gastric cancer with extensive lymph node metastasis: JCOG1002. Gastric Cancer 2017; 20(2): 322-331.

15. Cerullo V, Capasso C, Vaha-Koskela M, Hemminki O, Hemminki A. Cancer-Targeted Oncolytic Adenoviruses for Modulation of the Immune System. Curr Cancer Drug Targets 2018; 18(2): 124-138.

16. Costantini $C$, Bellet MM, Pariano $M$, Renga G, Stincardini C, Goldstein AL, Garaci E, Romani L. A Reappraisal of Thymosin Alpha1 in Cancer Therapy. Front Oncol 2019; 9: 873 . 